\title{
The Pneumatization of the Facial Skeleton in the Japanese Macaque (Macaca fuscata) — A Study Based on Computerized Three-Dimensional Reconstructions
}

\author{
ThOMAS KOPPE ${ }^{1}$, Yoshihiro INOUE ${ }^{1}$, Yoshio \\ HIRAKI $^{2}$, AND HIROSHI NAGAI ${ }^{1}$ \\ 1 Department of Anatomy, Okayama University School of \\ Dentistry, 2-5-1, Shikata-cho, Okayama, 700 Japan \\ 2 Department of Radiology, Okayama University School of \\ Medicine, 2-5-1, Shikata-cho, Okayama, 700 Japan
}

Received March 22, 1995

\begin{abstract}
Computerized three-dimensional images derived from coronal CT scan series of 10 adult skulls from Macaca fuscata of both sexes served to evaluate the paranasal sinuses. The maxillary sinus was found as the only paranasal sinus of the Japanese macaque. The hemispherical or kidney shaped maxillary sinus was almost restricted to the body of the maxilla. The maxillary sinus volume amounted to $0.88 \mathrm{~cm}^{3}$, with a bigger sinus in male than in female skulls. A regression analysis between the skull length and the maxillary sinus volume in the Japanese macaque and the same data of adult humans and great apes (Koppe and Schumacher, 1990) was carried out. Whereas close relations between these measurements were found in the hominoids, this relation was very weak in the Japanese macaque, suggesting that the primate maxillary sinus can't be explained solely by structural role.
\end{abstract}

Key Words: maxillary sinus, facial skeleton, Macaca fuscata, computed tomography, three-dimensional images

\section{INTRODUCTION}

The paranasal sinuses are typical formations of placental mammals (Moore, 1981; Lund, 1988). Within the hominoids they show not only a great variability in size and shape, but also a considerable enlargement. The latter is considered as a characteristic feature of the hominoids (Andrews and Martin, 1987). Concerning the significance of the paranasal sinuses uncountable theories have been developed (Blanton and Biggs, 1969; Blaney, 1986). However, the actual purpose of these structures remains largely unknown (Novacek, 1993). Because of the obviously close relation between the architecture of the skull and the paranasal sinuses morphology, numerous authors (e.g., Sperber, 1980, Blaney, 1986; Aiello and Dean, 1990) are convinced, that the paranasal sinuses lack in any functional role.

A review of the literature concerning the paranasal sinuses of primates shows that most investigations have dealt only with humans and great apes (Schaeffer, 1910; 
Cave and Haines, 1940; Wegner, 1955/56; Schumacher et al., 1972; Blaney, 1986; Koppe and Schumacher, 1992). There is a lack in information on the paranasal sinuses in non-human primates. Recently, Lund (1988) reported that several higher primates have no functional maxillary sinus while in other higher primates the maxillary sinus showed a wide range of size. However, since Lund (1988) has examined only one sample for each species, the significance of this study is of limited value.

The present study was designed to obtain morphological data on the paranasal sinuses in the Japanese macaque as well as to evaluate the hypothesis (Moore, 1981; Ward et al., 1982; Lund, 1988), that the size increase of the maxillary sinus during the primate evolution was mainly related to the skull size. Until now numerous studies on the craniofacial morphology and the dentition of the Japanese macaque have been carried out (Schweyer, 1909; Ikeda and Watanabe, 1966; Iwamoto et al., 1984, 1987; Fujiyoshi et al., 1990; Mouri, 1994). However, there are no data on the paranasal sinuses of the Japanese macaque so far.

\section{MATERIAL AND METHODS}

Ten adult skulls of the Japanese macaque (Macaca fuscata) of both sexes ( $\bigcirc$ males and $\bigcirc$ females), belonging to the Primate Research Institute, Kyoto University, were analyzed. All skulls were examined using a computed tomograph GE CT HiSpeed Advantage RP in the Department of Radiology, Okayama University School of Medicine. The distances between the coronal CT scans amounted to $1 \mathrm{~mm}$. The scanning parameters were $120 \mathrm{kV}$ and $150 \mathrm{~mA}$.

The CT scan images were analyzed with the ALLEGRO software program (ISG Technologies Inc., Toronto). Briefly, on each CT scan image the outline of the maxillary sinus was surrounded with a cursor. Based on these data, threedimensional (3-D) image reconstructions of the maxillary sinus were made and the volume of the sinuses was measured (Table 1). In addition, 3-D images of neighbouring structures such as the maxillary teeth, were made.

Table 1. Data base for the quantitative analysis

\begin{tabular}{cccccc}
\hline \multicolumn{3}{c}{ Macaca fuscata - male } & \multicolumn{3}{c}{ Macaca fuscata-female } \\
\hline $\begin{array}{c}\mathrm{Vr} \\
\left(\mathrm{cm}^{3}\right)\end{array}$ & $\begin{array}{c}\mathrm{Vl} \\
\left(\mathrm{cm}^{3}\right)\end{array}$ & $\begin{array}{c}\mathrm{SL} \\
(\mathrm{cm})\end{array}$ & $\begin{array}{c}\mathrm{Vr} \\
\left(\mathrm{cm}^{3}\right)\end{array}$ & $\begin{array}{c}\mathrm{Vl} \\
\left(\mathrm{cm}^{3}\right)\end{array}$ & $\begin{array}{c}\mathrm{SL} \\
(\mathrm{cm})\end{array}$ \\
\hline 0.716 & 0.604 & 13.49 & 0.330 & 0.336 & 13.85 \\
1.416 & 1.017 & 13.86 & 1.448 & 1.271 & 12.31 \\
1.583 & 1.169 & 14.19 & 0.454 & 0.479 & 11.80 \\
0.487 & 0.828 & 13.70 & 1.042 & 1.167 & 12.41 \\
0.752 & 0.767 & 13.32 & 0.597 & 0.612 & 12.01 \\
\hline
\end{tabular}

$\mathrm{Vr}$ - right maxillary sinus volume, $\mathrm{Vl}$ - left maxillary sinus volume, SL - skull length 
Means and standard deviation of the maxillary sinus volume were calculated for both male and female skulls. The sexual dimorphism of the maxillary sinus size was tested by employing the two-tailed $t$-test (Table 2 ). To analyze the relation between the skull size and the maxillary sinus volume, a simple regression analysis $(P<0.05)$ was performed. The skull length (opisthocranion-prosthion) served as an indicator of the skull size (Blaney, 1986). Apart from the data of the Japanese macaque, in this regression analysis the values for the maxillary sinus volume as well as the skull length for humans and great apes obtained by Koppe and Schumacher (1990) were included (Table 3.)

Table 2. Means, standard deviations and results of the two-tailed $t$-test, Macaca fuscata, results in $\mathrm{cm}^{3}$

\begin{tabular}{lccccc}
\hline & \multicolumn{2}{c}{ male } & \multicolumn{2}{c}{ female } & \\
\cline { 2 - 5 } & Mean & S.D. & Mean & S.D. & $t$ \\
\hline right maxillary sinus volume & 0.991 & 0.479 & 0.774 & 0.463 & $0.785^{\text {ns }}$ \\
left maxillary sinus volume & 0.877 & 0.220 & 0.773 & 0.420 & $0.557^{\text {ns }}$ \\
\hline
\end{tabular}

ns - not significant

Table 3. Data base for quantitative analysis, Hominoidea

\begin{tabular}{rrccccccccccc}
\hline & Man & \multicolumn{4}{c}{ Chimpanzee } & \multicolumn{3}{c}{ Gorilla } & \multicolumn{3}{c}{ Orang-Utan } \\
\hline Sex & $\begin{array}{c}\text { Vr } \\
\left(\mathrm{cm}^{3}\right)\end{array}$ & $\begin{array}{c}\text { SL } \\
(\mathrm{cm})\end{array}$ & Sex & $\begin{array}{c}\text { Vr } \\
\left(\mathrm{cm}^{3}\right)\end{array}$ & $\begin{array}{c}\text { SL } \\
(\mathrm{cm})\end{array}$ & Sex & $\begin{array}{c}\mathrm{Vr} \\
\left(\mathrm{cm}^{3}\right)\end{array}$ & $\begin{array}{c}\text { SL } \\
(\mathrm{cm})\end{array}$ & Sex & $\begin{array}{c}\text { Vr } \\
\left(\mathrm{cm}^{3}\right)\end{array}$ & $\begin{array}{c}\text { SL } \\
(\mathrm{cm})\end{array}$ \\
\hline M & 12.62 & 20.6 & M & 20.40 & 19.5 & M & 40.11 & 27.5 & M & 27.49 & 21.5 \\
M & 19.60 & 20.7 & M & 15.80 & 20.0 & M & 58.79 & 27.8 & M & 26.17 & 20.4 \\
M & 9.37 & 18.4 & M & 24.18 & 20.0 & M & 27.05 & 30.1 & M & 52.08 & 22.8 \\
M & 8.14 & - & M & 22.12 & 19.6 & M & 58.56 & 33.5 & M & 22.21 & 21.4 \\
M & 15.95 & 21.0 & M & 20.56 & 17.0 & M & 20.34 & 29.6 & M & 22.53 & 20.7 \\
M & 12.36 & 19.7 & F & 22.95 & 18.5 & F & 35.68 & 27.8 & M & 13.20 & 16.5 \\
M & 3.68 & 19.0 & F & 16.62 & 17.5 & F & 24.77 & 22.1 & M & 32.53 & 16.8 \\
M & 11.47 & 18.1 & F & 15.08 & 17.3 & F & 59.44 & 24.9 & F & 27.03 & 18.4 \\
F & 21.25 & 20.0 & F & 20.88 & 17.5 & F & 25.97 & 21.3 & F & 16.65 & 17.7 \\
F & 10.72 & 19.6 & F & 11.29 & 17.0 & F & 47.67 & 22.0 & F & 11.9 & 22.5 \\
& & & & & & & & & F & 19.93 & 20.5 \\
\hline
\end{tabular}

$\mathrm{Vr}$ - right maxillary sinus volume, $\mathrm{SL}$ - skull length, $\mathrm{M}$ - male, $\mathrm{F}$ - female

\section{RESULTS}

It was found, that the paranasal sinuses of Macaca fuscata consist only of paired maxillary sinuses (Figs. 1, 2).The evaluation of the coronal CT scans showed, that there was also a kind of pneumatization of the interorbital septum (Fig. 3c). However, real ethmoidal air cells could not be observed.

The 3-D images revealed the maxillary sinus as a hemispherical or kidney shaped 

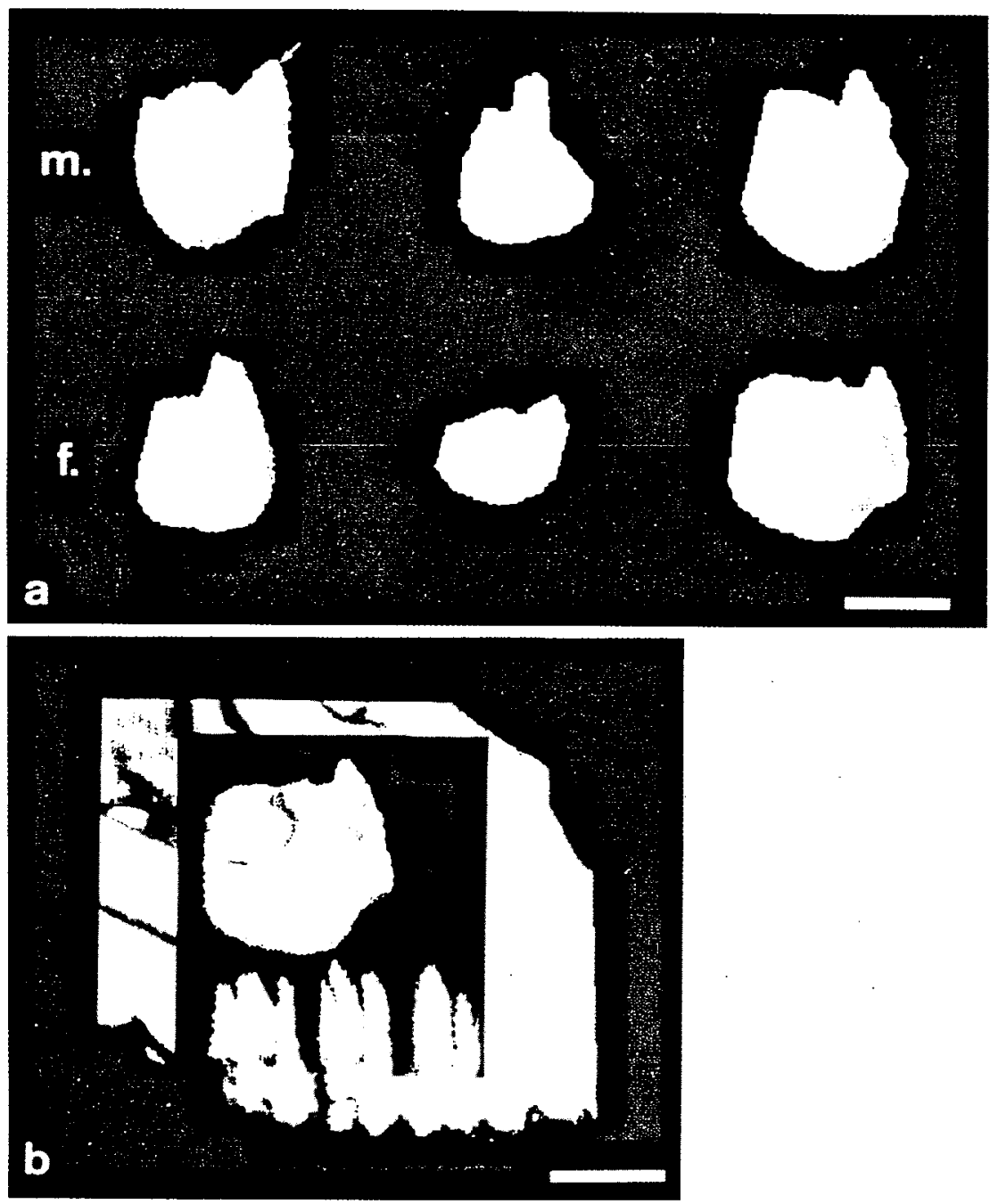

Fig. 1. Lateral view of the three-dimensional maxillary sinus' reconstructions of Macaca fuscata. a. A comparison of the maxillary sinus in male (m.) and female (f.) monkeys. The arrow points at the frontal recess of the maxillary sinus. b. Relationship of the maxillary sinus (red) to the roots of the upper molars (yellow) in a female skull of Macaca fuscata. Bars: $1 \mathrm{~cm}$.

structure with the base on the medial side directed towards the nasal cavity (Fig. 2c). The maxillary sinus was restricted to the body of the maxilla in the region of the second and third upper molar (Fig. 1b). The convex surface of the sinus was directed laterally to the zygomatic bone. However, the sinus did not extend laterally to the zygomaticomaxillary suture (Fig. 3d). The whole roof of the sinus was formed by the orbital floor. In some samples the sinus showed a small frontal recess. The 

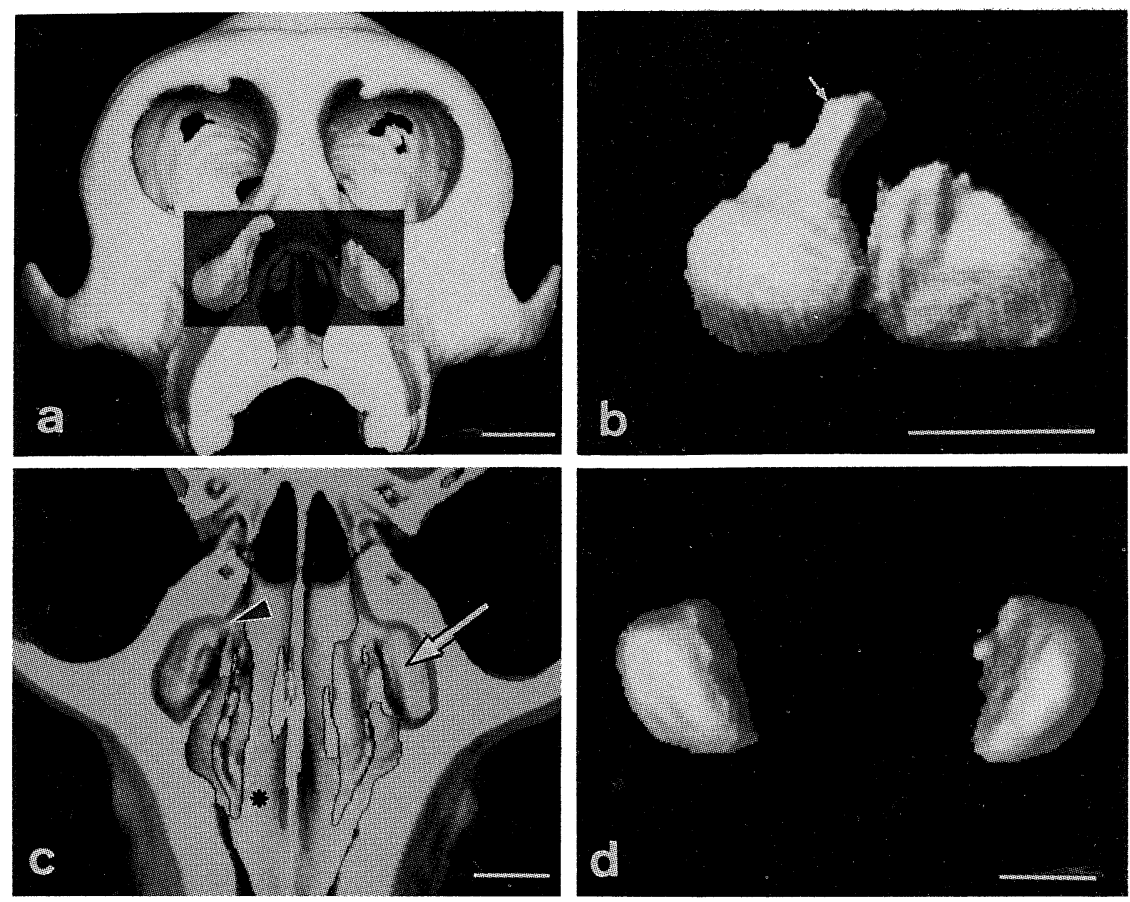

Fig. 2. Three-dimensional reconstructions of the maxillary sinus and parts of the skull of a male Japanese macaque from different views. a. Topography of the maxillary sinus in an anterior view. b. Reconstruction models of the right and left maxillary sinus from oblique-lateral view. The frontal recess of the right maxillary sinus is marked by an arrow. c. Reconstruction model of a skull at a view from superior. The model has been cut transversally at the level of zygomatic arches to demonstrate the maxillary sinus (arrow). Note that the maxillary sinus ostium (arrow-head) opens in the posterior part of the nasal cavity (asterisk). d. Inferior view of the right and left maxillary sinus showing the smooth surface of the maxillary sinus floor. Bars: $1 \mathrm{~cm}$.

floor of the maxillary sinus was seen in all samples clearly above the level of the root apices of the maxillary molars. The lingual root of the second upper molar showed the closest relation to the floor of the maxillary sinus (Fig. 1b).

Table 1 contains the data base for the statistical analysis. Although the volume of the male maxillary sinus was greater than that of the female, the sex difference was not significant (Table 2). Figure 4 shows the result of the regression analysis for the log-transformed data of hominoids. The comparison of the maxillary sinus volume with the skull length showed a significant relation between these measurements for the hominoids. The values for Macaca fuscata, however, were quite far from the regression line, indicating that the difference in the maxillary sinus volume between hominoids and the Japanese macaque can't be explained only by the difference in skull size. 

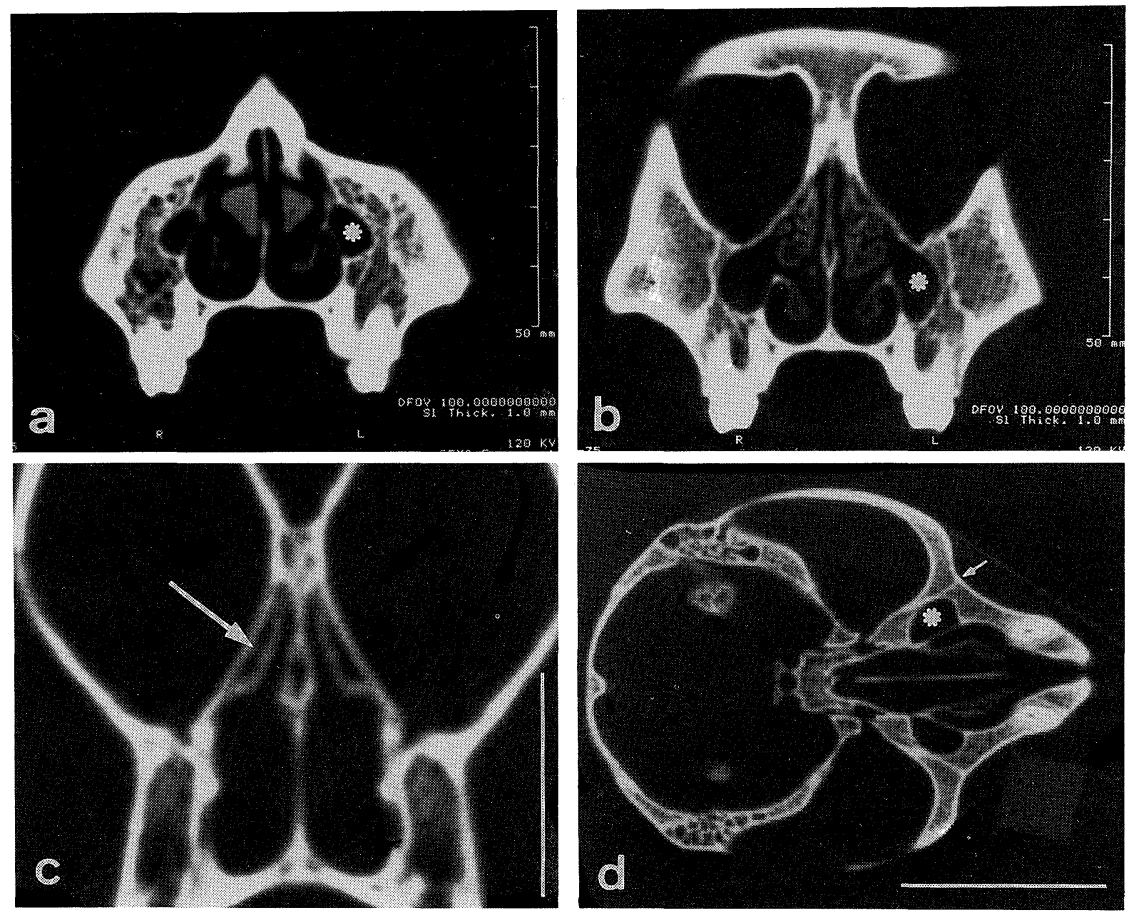

Fig. 3. CT scans of skulls of Japanese monkeys at different cut planes to demonstrate the pneumatization of the facial skeleton. The left maxillary sinus is marked by an asterisk. a. Male Japanese monkey, coronal CT scan through the second upper molar. b. Male Japanese monkey, coronal CT scan through the third upper molar. c. Male Japanese monkey, coronal CT scan through the posterior margin of the hard palate. Note the pneumatization of the ethmoid bone (arrow). d. Female Japanese macaque, horizontal CT scan through the zygomatic arch. Note, that maxillary sinus (asterisk) does not extend laterally to the zygomaticomaxillary suture (arrow). Bars: $5 \mathrm{~cm}(\mathbf{a}, \mathbf{b}, \mathbf{d}), 2 \mathrm{~cm}(\mathbf{c})$.

\section{DISCUSSION}

The present study verified that the extent of pneumatization in the Japanese macaque differs considerably from those found in extant hominoids (Fig. 5). While in humans and in great apes in particular, the maxillary sinus virtually occupies the whole maxilla and may also invade neighboring bones (Cave and Haines, 1940; Moore, 1981), the sinus of the Japanese macaque is restricted only to the body of the maxilla. Thus, the region of the maxilla beyond the upper molar appears quite robust.

It is of interest to note, that the interorbital region of the Japanese macaque was partially pneumatized (Fig. 3c). According to Cave and Haines (1940) as well as Blaney (1986) ethmoidal air cells are restricted only to humans and African great apes. Cave and Haines (1940) have pointed out that the appearance of ethmoidal 


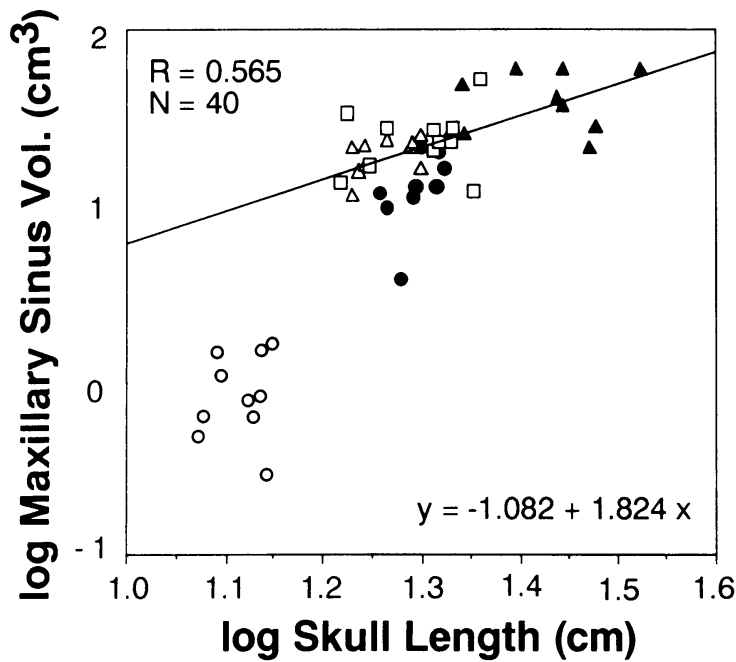

- Human

$\triangle$ Chimpanzee

$\Delta$ Gorilla

Orang-Utan

Japanese Macaque

Fig. 4. Bivariate logarithmic plot illustrating the relationship between the maxillary sinus volume and the skull length for adult skulls of Hominoidea and Macaca fuscata. In the case of the Japanese macaque, the values are transposed clearly below the regression line for the Hominoidea.

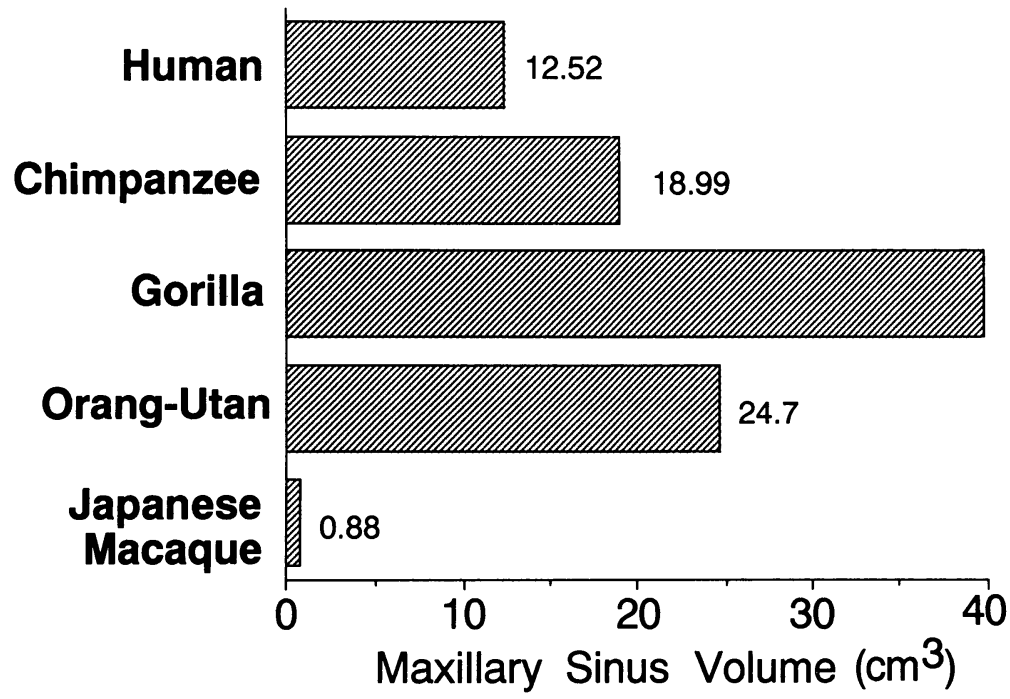

39.84

Fig. 5. Means of the right maxillary sinus volume for hominoids and the Japanese macaques. The sexes are pooled.

air cells is important in terms of phylogeny. However, a pneumatization of the interorbital region occurs obviously much earlier. This is not only demonstrated in the present study, but also in previous investigations in Lemur, Alouatta and 
Cebus (Wegner, 1955/56) as well as in orang-utan (Wegner, 1955/56; Koppe and Schumacher, 1992).

The close relationship between the roots of the maxillary teeth and the maxillary sinus floor is of great clinical significance. In hominoids, the alveolar recess of the maxillary sinus may deeply invade the alveolar process and the alveoli of the maxillary molars and premolars are sometimes exposed as bulges (Cave and Haines, 1940; Ward and Pilbeam, 1983). Based on the study of several extant and extinct hominoids, Ward et al. (1982) suppose that the size of the maxillary sinus as well as its enlargement into the alveolar process is a function of body size. In contrast to the hominoids, the present study showed the maxillary sinus floor in Macaca fuscata clearly above the level of the root apices of the maxillary molars. In addition, serial coronal CT scans through the maxillary sinus of Macaca fuscata as well as 3-D images demonstrated the smooth surface of the maxillary sinus floor (Fig 2d). The enlargement of the maxillary sinus into the alveolar recess may indeed be influenced by the body size in hominoids, however, this relationship seems to be different in other non-human primates. This conclusion can be drawn also from Lund's (1988) study on the maxillary sinus size in numerous species of higher primates. He has demonstrated, that the maxillary sinus of some primates with large body size such as Mandrillus and Papio appears only as small lateral recess while in primates with considerable smaller body size such as Aotus and Cebus the maxillary sinus was relatively big.

With regard to the complicated shape of the paranasal sinuses, volume measurements are probably most suitable for scaling the size of the paranasal sinuses (Schumacher et al., 1972). While plain radiographs and two-dimensional CT scans allow only partially to evaluate the paranasal sinuses, by means of computer reconstruction of serial CT scans, it is possible to get information of both the volume and the shape of the paranasal sinuses. This method is especially recommended in species with a small degree of pneumatization such as Macaca fuscata. The volume of the maxillary sinus in the Japanese macaque amounted to less than $1 \mathrm{~cm}^{3}$. Although there are no reports on the maxillary sinus volumes in other primates than great apes and humans, the data on the maxillary sinus size of different Cebidae and Cercopithecidae provided by Lund (1988) indicate, that the degree of pneumatization of the Japanese macaque is relatively small.

Numerous studies have confirmed a certain degree of sexual dimorphism in size of the paranasal sinuses of humans (Schürch, 1906; Schaeffer, 1910; Szilvássy, 1974; Nowak and Mehlis, 1975) and the great apes (Blaney, 1986). The present study, however, revealed only a small degree of sexual dimorphism in the maxillary sinus size of Macaca fuscata. This result is to some degree surprising, since studies by Ikeda and Watanabe (1966) and Mouri (1994) showed that in most external cranial dimensions male Japanese macaques are larger than female. Moreover, 
Mouri (1994) pointed out, that highly significant sex differences tend to be found in facial dimensions. Thus, the small sex difference in the maxillary sinus size found in this study, may be partially due to the small number of skulls. On the other hand, the fact that the maxillary sinus pneumatized only a relatively small part of the maxilla in Macaca fuscata, indicates that shape and size of the maxillary sinus are less related to the external skull architecture than in hominoids. Therefore, the small degree of sexual dimorphism in sinus size of the Japanese macaque may be also related to the topography of the maxillary sinus. Because the precise origin of the skulls used in the present study is not known, it is possible that the geographic origin of the skulls had also a certain effect on the data. This assumption is based on recent investigations on the crab-eating macaque by Fooden and Albrecht (1993). This study gives some evidence that the skull size of a primate species may also vary according to their distribution. Moreover, Hamada (1994) has demonstrated, that different groups of Macaca fuscata may grow according to a different growth pattern.

Lund (1988) argues that in those monkeys with a maxillary sinus, the sinus size increases with the size of the skull. This conclusion can also be drawn from studies on the frontal sinus in African great apes (Blaney, 1986) as well as the maxillary sinus in hominoids in the present investigation (Fig. 4). However, the present study showed, that the maxillary sinus size of the Japanese macaque is obviously less related to the skull size. Thus, the results of the present study suggest that the size increase of the maxillary sinus within the primate evolution can't be explained satisfactorily only by the increasing skull size. Notwithstanding that development and growth of the maxillary sinus are closely related to the growth of the skull and to the dentition (Wolf et al., 1993), it has been demonstrated that the sinuses also possess a developmental potential of their own (Libersa et al., 1991; Koppe et al., 1994). On the other hand, recent studies by Francis et al. (1990) and Oktay (1992), who have revealed that neither cleft lip and palates nor orthodontic malocclusion affect the size of the maxillary sinus, give some doubts about an exclusive structural role of the paranasal sinuses. To strengthen this assumption further analyses in a wide range of non-human primates are necessary.

\section{ACKNOWLEDGEMENTS}

This study was supported by the Cooperation Research Program of the Primate Research Institute, Kyoto University. We are grateful to Prof. M. Iwamoto, Prof. T. Kimura, Dr. T. Mouri and Dr. Y. Kunimatsu, Primate Research Institute of the Kyoto University, for valuable advice and support. The great support and advice of Mr. Yoshihiro Ohkawa, Central Division of Radiology of the Okayama University Hospital, during the whole examination period was much appreciated. 


\section{REFERENCES}

Aiello, L., and Dean, C. (1990) An Introduction to Human Evolutionary Anatomy, Academic Press, London.

Andrews, P., and Martin, L. (1987) Cladistic relationships of extant and fossil hominoids. J. Hum. Evol. 16, 101-118.

Blaney, S.P.A. (1986) An allometric study of the frontal sinus in Gorilla, Pan and Pongo. Folia Primatol. 47, 81-96.

Blanton, P.L., and Biggs, N.L. (1969) Eighteen hundred years of controversy: The paranasal sinuses. Am. J. Anat. 124, 135-148.

Cave, A.J.E., and Haines, R.W. (1940) The paranasal sinuses of the anthropoid apes. J. Anat. 72, 493-523.

Fooden, J., and Albrecht, G.H. (1993) Latitudinale and insular variation of skull size in crab-eating macaques (Primates, Cercopithecidae: Macaca fascicularis). Am. J. Phys. Anthropol. 92, 521-538.

Francis, P., Raman, R., Korula, P., and Korah, I. (1990) Pneumatization of the paranasal sinuses (maxillary and frontal) in cleft lip and palate. Arch. Otolaryngol. Head Neck Surg. 116, 920-922.

Fujiyoshi, T., Watanabe, T., and Mogi, G. (1990) Three-dimensional images of the temporal bone and experimental otitis media in Japanese monkeys. Arch. Otolaryngol. Head Neck Surg. 116, 813-819.

Hamada, Y. (1994) Standard growth patterns and variations in growth patterns of the Japanese Monkeys (Macaca fuscata) based on analysis by the spline function method. Anthropol. Sci. 102 (Suppl.), 57-76.

Ikeda, J., and Watanabe, T. (1966) Morphological studies of Macaca fuscata. III. Craniometry. Primates 7, 271-288.

Iwamoto, M., Hamada, Y., and Watanabe, T. (1984) Eruption of the deciduous teeth in Japanese monkeys (Macaca fuscata). J. Anthrop. Soc. Nippon 92, 273-279.

Iwamoto, M., Watanabe, T., and Hamada, Y. (1987) Eruption of permanent teeth in Japanese monkeys (Macaca fuscata). Primate Res. 3, 18-28.

Koppe, T., and Schumacher, K.U. (1990) Vergleichend-anatomische Untersuchungen zur funktionellen Morphologie der Nasennebenhöhlen des Menschen und der Pongiden. Eine quantitative Studie auf der Grundlage der Computertomographie. Med. Dissertationsschr. B, Rostock.

Koppe, T., and Schumacher, K.U. (1992) Untersuchungen zum Pneumatisationsgrad des Viscerocranium beim Menschen und bei den Pongiden. Acta Anat. Nippon 67, 725-734.

Koppe, T., Yamamoto, T., Tanaka, O., and Nagai, H. (1994) Investigations on the growth pattern of the maxillary sinus in Japanese human fetuses. Okajimas Folia Anat. Jpn. 70, 311-318.

Libersa, C., Laude, M., and Libersa, J.C. (1981) The pneumatization of the accessory cavities of the nasal fossae during growth. Anat. Clinica 2, 265-273.

Lund, V.J. (1988) The maxillary sinus in the higher primates. Acta Otolaryngol. 105, 164-171.

Moore, W.J. (1981) The Mammalian Skull, Cambridge Univ. Press, Cambridge, London.

Mouri, T. (1994) Postnatal growth and sexual dimorphism in the skull of the Japanese macaque (Macaca fuscata). Anthropol. Sci. 102 (Suppl.), 43-56.

Novacek, M.J. (1993) Patterns of diversity in the mammalian skull. In The Skull, Vol. 2. (Hanken, J., and Hall, B.K., ed.), Univ. of Chicago Press, Chicago, London, pp. 438-545.

Nowak, R., and Mehlis, G. (1975) Untersuchungen zum Verhalten der Pneumatisation des Sinus maxillaris. Anat. Anz. 138, 143-151.

Oktay, H. (1992) The study of the maxillary sinus areas in different orthodontic malocclusions. Am. J. Orthod. Dentofac. Orthop. 102, 143-145. 
Schaeffer, J.P. (1910) The sinus maxillaris and its relations in the embryo, child and adult man. Am. J. Anat. 10, 313-368.

Schumacher, G.H., Heyne, K.J., and Fanghänel, R. (1972) Zur Anatomie der menschlichen Nasennebenhöhlen. 2. Volumetrie. Anat. Anz. 130, 132-157.

Schürch, O. (1906) Ueber die Beziehungen der Grössenvariationen der Highmorshöhlen zum individuellen Schädelbau und deren praktische Bedeutung für die Therapie der Kieferhöhleneiterungen. Arch. Laryngol. 18, 229-257.

Schweyer, P. (1909) Der Schädel von Inus speciosus japonensis, sein Variationskreis und Zahnbau. Inaug.-Diss., München.

Sperber, G.H. (1980) Applied anatomy of the maxillary sinus. J. Can. Dent. Assoc. 6, 381-386.

Szilvássy, J. (1974) Die Stirnhöhlen aus dem awarischen Gräberfeld von Zwölfaxing in Niederösterreich. Ann. Naturhist. Mus. Wien 78, 109-118.

Ward, S.C., Johanson, D.C., and Coppens, Y. (1982) Subocclusal morphology and alveolar process relationships of hominoid gnathic elements from the Hadar formation: 1974-1977 collections. Am. J. Phys. Anthropol. 57, 605-630.

Ward, S.C., and Pilbeam, D.R. (1983) Maxillofacial morphology of miocene hominoids from Africa and Indo-Pakistan. In New Interpretations of Ape and Human Ancestry (Ciochon, R.L., and Corruccini, R.S., ed.) Plenum Press, New York, London, pp. 211-238.

Wegner, R.N. (1955/56) Studien über die Nebenhöhlen des Schädels. Verschmelzungen der Nebenhöhlen der Nase und Abänderungen ihrer Öffnungen bei Primaten. Wiss. Z. Ernst-Moritz-Arndt-Univ. Greifswald, Math. Naturwiss. Reihe 5, 1-39.

Wolf, G., Anderhuber, A., and Kuhn, F. (1993) Development of the paranasal sinuses in children: implications for paranasal sinus surgery. Ann. Otol. Rhinol. Laryngol. 102, 705-711. 